\title{
Modeling Market Integration and Asymmetric Price Transmission Dynamics of Yam Markets in Ghana
}

\author{
Isaac Abunyuwah \\ Department of Agriculture Economics \& Extension, College of Agriculture Education, \\ University of Education, Winneba Ghana \\ iabunyuwah@hotmail.com
}

\begin{abstract}
Functioning agricultural markets are fundamental to unlock economic growth and to accelerate agricultural development. Understanding the behavior of agriculture markets is crucial for price, poverty and livelihood policy strategies in agrarian economies. To assess price transmission and market efficiencies of Ghanaian yam markets spatial market integration analysis of five major yam markets: Techiman, Tamale, Wa, Kumasi and Accra was conducted. Monthly wholesale price data between January 2006 and June 2018 were used. Results from the momentum threshold autoregressive (M-TAR) model indicated the presence of cointegration and price transmission asymmetries. Thus, price increases in Techiman reference market are more rapidly transmitted to the other regional markets than price reductions. It is recommended that the source of this type of asymmetry be investigated as it favors middlemen at the expense of producers and retailers/consumers for appropriate marketing policy intervention.
\end{abstract}

Keywords: Ghana, Spatial Market Integration, Asymmetric price transmission, momentum threshold autogressive model.

\section{Introduction}

The issues of agricultural market restructuring, price transmission dynamics and efficiency in developing countries have gained considerable attention over the past two decades. This is due to the complexities and imperfections that have characterized interconnections among producers, wholesalers, retailers, and other market agents in a multifaceted structure. The efficient operation of agricultural markets relies extensively on the momentum of price transmission within and across markets in both vertical and horizontal directions across a country. Thus, understanding the relationships among market agents is a key to establishing marketing efficiency, consumer and producer welfare levels (Lemma and Singh, 2015). In agricultural market analysis, and price transmission studies in particular, evidence of asymmetric adjustments carries important theoretical and policy implications as it concerns consumer and producer welfare; equilibrium dynamics, market power and efficiency; and market policy effectiveness. Consequently, empirical studies in market integration (MI) analysis have received a lot of attention over the past five decades in both outcomes and methods. For instance, studies that found presence of asymmetric price transmission adjustment processes or non-cointegrated relationships generated market power and imperfections concerns. With respect to methods, while many earlier studies assumed linear relationships between inter-markets price responses and as a result applied linear econometric models, over the past decade, many researchers have presented arguments for nonlinearities.

In market integration and price transmission mechanisms (Baulch, 1997; von Cramon, 1998; Barrett and Li, 2002; Zapata and Gauthier, 2003; Abunyuwah, 2008, 2013). Presence of strongly integrated markets across space ensures the prevalence of the law of one price and in effect reduces price variability and its adverse consequences on consumer and producers' resource utilization behaviors. Despite continued, direct and indirect, calls for and implementation of agricultural market and trade based policy strategies to improving market accessibility, integration and efficiency, observed activities of agricultural market intermediaries and nested variations in prices within and across production seasons between producer markets and others in Ghana call for deeper insights and evaluation of price formation dynamics and levels of agricultural market interconnectedness. One crop which has received little attention in the MI literature is Yam. In Ghana yam is an essential crop for both commercial and subsistence production, almost across all regions of the country. In terms of production, Ghana ranks third in the world, following Nigeria and Cote d'Ivoire and yam accounts for about $16 \%$ of agricultural gross domestic product (GDP) (FAOSTAT, 2014). Domestically yam is widely produced, consumed and traded across the country providing economic livelihood for many actors involved in its supply and value chains. Despite its significance in the livelihood of agents involved in its production, distribution and marketing of the commodity, little or no study has emphasized. 
On the price transmission dynamics and market integration analysis to appropriately inform policy recommendations. Yam production in Ghana like many others requires efficient markets to ensure that producers receive appropriate prices for their produce. To understand the Ghanaian yam markets dynamics and implied efficiency, the study was set to examine the spatial price transmission mechanisms within Ghana's yam markets through non-linear cointegration approach. This is to provide empirical basis for policy recommendations on the functioning structure of the major yam markets in Ghana.

\section{Related Studies}

In agricultural based economies, market efficiency and active market participation of smallholder farmers are necessary for sustained livelihood improvements and economic development. In market efficiency assessments price transmission and spatial market integration analyses have been adopted. For its theoretical, policy and welfare implications, extensive MI studies abound for both developed and developing agricultural markets worldwide. Popular market integration (MI) studies in Ghana include (Abdulai, 2000; Alderman, 1992; Badiane and Shively, 1998) who reported varied degree of price transmission adjustments, asymmetric responses and long-run interrelationships in the Ghanaian food markets. Explaining price adjustment processes Badiane and Shively (1998) reported that price transmission dynamics were responsive to the degree of market interconnectedness to the reference market using cointegration analysis. Employing threshold cointegration analysis Abdualai (2000) reported that wholesale maize prices from (Accra and Bolgatanga) respond asymmetrically to price changes in Techiman market. Similar to studies that found price transmission asymmetries, it was observed that responses were slower when margins were stretched by price decreases in the central market (see von Cramon, 1998). In Amikuzuno (2009), it was reported that degree and speed of spatial price transmission within fresh tomato markets in Ghana varied in space and across tariff policy regimes. Applying threshold autoregressive (TAR) model, he found that price transmission between some market pairs improved while others deteriorated during low tariffs regime. The study also reported an improvement in the speeds of price adjustment and integration under low tariff regime.

Employing the Johansen multivariate co-integration analysis and error correction model, Mensah-Bonsu et al. (2011) assessed the efficiency of the plantain marketing system in Ghana and concluded that price transmission and market integration between the central consumption market and others were weak. Acquah (2012) studied retail and wholesale maize markets in Ghana using vertical price transmission framework. The researcher found that the markets were cointegrated and exhibited threshold effects with asymmetric price adjustments in which negative deviations from long-term equilibrium reverted faster than for positive deviations. Assessing price transmission dynamics of imported and local wholesale rice prices from 2006 to 2011 in Ghana, Amikuzuno et al. (2013) observed in the presence of long-run equilibrium relationships that imported rice prices responded partially to price shocks from the local market. With methodological focus, Abunyuwah (2013), building on (Baulch, 1997; von Cramon, 1998; Barrett and Li, 2002) in particular demonstrated with synthesized data how various relative non-linear data complexities impose limitations on linear and simple non-linear time series econometric models under specific market equilibrium assumptions. Blay et al. (2015) studied price volatility, market integration and price transmission adjustments of sorghum and millet markets in Ghana using both the framework of M-TAR and threshold vector error correction models. They reported that for both commodities, the markets and their respective reference markets emitted asymmetric adjustment processes towards the long-run equilibrium where relatively high persistence characterized positive deviations as compared to negative deviations. The study also reported higher levels of price instability and risk.

\section{Methodology and Data}

The present study focuses on price transmission dynamics of major yam markets in Ghana. Data set for the analysis was a time series of yam monthly wholesale prices spanning from January 2006 to June 2018. Techiman, Kumasi, Tamale, Accra and Wa markets, been major yam and bigger markets in Ghana were purposively used for the study. The Techiman market was selected as the reference market. The underlying data generating process (DGP) of the variables were first assessed by testing for the presence of unit root properties and seasonal patterns using the standard augmented Dickey-Fuller (ADF) and Kwiatkowski- 
Phillips-Schmidt-Shin (KPSS) unit root tests and the seasonal unit root test developed by Hylleberg et al. (1990) respectively as many economic time series variables exhibit these characteristics. The model for the monthly data was specified as:

$$
\begin{gathered}
\Delta_{12} y_{t}=\pi_{1} z_{1, t-1}+\pi_{2} z_{2, t-1}+\pi_{3} z_{3, t-1}+\pi_{4} z_{3, t-2}+\pi_{5} z_{4, t-1}+\pi_{6} z_{4, t-2}+\pi_{7} z_{5, t-1}+\pi_{8} z_{5, t-2}+\pi_{9} z_{6, t-1} \\
+\pi_{10} z_{6, t-2}+\pi_{11} z_{7, t-1}+\pi_{12} z_{7 t-2}+\sum_{j=1}^{p} \alpha_{j}^{*} \Delta_{12} y_{t-j}+\mu_{t}
\end{gathered}
$$

The null hypotheses $H_{0}: \pi_{1}=0, H_{0}: \pi_{2}=0$ and $H_{0}: \pi_{1}=\pi_{2}=0$ correspond to tests for regular, semi-annual and annual unit roots respectively.

Threshold Cointegration: In the traditional cointegration modeling framework asymmetric adjustments are not directly captured as the models are built within linear and symmetric equilibrium structure (Balk and Fomby, 1997; Enders and Siklos, 2001). Taking into consideration high incidence of price transmission asymmetries reported by researchers over the past three decades and their modeling implications in time series MI analysis, we employed an asymmetric model (M-TAR) of Enders and Siklo (2001) in the cointegration analysis of yam markets in Ghana. The threshold autoregressive model was expressed as

$$
\Delta \mu_{t}=M_{t} \rho_{1} \mu_{t}+\left(1-M_{t}\right) \rho_{2} \mu_{t-1}+\sum_{i=1}^{p} \gamma_{i} \Delta \mu_{t-i}+\omega_{t}
$$

Where $M_{t}=\left\{\begin{array}{l}1 \text { if } \Delta \mu_{t-1} \geq \Psi \\ 0 \text { if } \Delta \mu_{t-1}<\Psi\end{array}\right.$

Where $\mathrm{M}_{\mathrm{t}}$ is the Heaviside indicator function; $\Psi$ defines the threshold point value; $\rho_{1}$ and $\rho_{2}$ represent the cointegration parameters; and $\omega_{t}$ is made up of zero-mean, constant variance errors, such that $\omega_{t}$ is independent of the residuals from the yam prices specification, $\mu_{\mathrm{t}}$. The test for no co-integration ( $\rho_{1}=\rho_{2}=0$ ) in the model is of a nonstandard joint F-test $\left(\Phi_{i}\right)$, where the test statistic $\Phi_{i}(i=$ MTAR ) is compared to critical values of those provided by Enders and Siklos (2001). In the estimation of M-TAR, the $\Psi \mathrm{s}$ are usually unknown and are estimated. We used Chan's (1993) approach in the estimation of the threshold value $(\Psi)$ and employed the two-step approach for analyzing the price transmission dynamics mechanisms. First, we tested for the presence of cointegration against the null hypothesis of no cointegration in the linear framework.

Next, after the null hypothesis of no cointegration was rejected, a test of linear against threshold cointegration was conducted along Hansen-Seo's (2002) lagrangian multiplier (LM) test. The structure of the model under the null hypothesis of "no threshold effect" reduces to a linear Vector Error Correction Model (VECM), and this is compared to its alternative nonlinear model structure that incorporates threshold effects. In order to incorporate the threshold and asymmetric non-linearities, the threshold vector error correction model (TVECM) as expressed in equation (2) was adopted for the study. Threshold cointegration has become one of the popular modeling approaches for dealing with the combination of both asymmetries and cointegration which captures nonlinear adjustment towards long-run equilibrium, thus making it feasible for studying the dynamics of market integration and price transmission processes (Abdulai, 2002; Jawadi et al., 2009), under non-multiple equilibria assumption (Abunyuwah, 2008; 2013).

$$
\Delta P_{t}= \begin{cases}\rho_{1} \gamma^{\prime} P_{t-1}+\theta_{1}+\sum_{m=1}^{M} \circledast_{1 m} \Delta P_{t-m}+\varepsilon_{t}, & \left.\gamma^{\prime} P_{t-1} \leq \Psi \text { (Regime } 1\right) \\ \rho_{2} \gamma^{\prime} P_{t-1}+\theta_{2}+\sum_{m=1}^{M} \circledast_{2 m} \Delta P_{t-m}+\varepsilon_{t}, & \Psi<\gamma^{\prime} P_{t-1} \text { (Regime 2) }\end{cases}
$$

In equation (2) $\Psi$ defines the threshold parameter. The TVECM explains price $\left(P_{t}\right)$ changes by lag price adjustments in both short term and long term, but conditionally on the magnitude of the deviation from the long term equilibrium $\left(\gamma^{\prime} P_{t-1}\right)$. Lags length $(\mathrm{n})$ used in the model were determined by using Bayesian Information Criterion (BIC). 


\section{Results and Discussion}

Seasonality and Unit Root Test: The results of the HEGY test are presented in Table 1. The results from the test indicate that among all the series, the presence of unit root at the zero frequency could not be rejected at any of the conventional levels of significance. For the rest of the frequencies, unit roots were rejected in all the series with the exception of Tamale market series. The Tamale series exhibited seasonal unit root at all frequencies. Therefore, in addition to the long run unit root that characterized all series, some series were affected by seasonal unit roots. The seasonality pattern in some of the series could be attributed to weather, market and other technological effects. In effect seasonality was treated deterministically and all further analyses were based on the seasonally adjusted data.

Table 1: Results of HEGY Test

\begin{tabular}{|c|c|c|c|c|c|c|}
\hline VARIABLE & ACCRA & KUMASI & TAMALE & TECHI & WA & FREQ \\
\hline$\pi_{1}$ & 3.143 & -0.067 & 2.489 & 0.389 & 2.048 & 0 \\
\hline$\pi_{2}$ & 1.597 & 2.539 & 2.586 & -0.756 & 2.296 & $\pi$ \\
\hline$\pi_{3}=\pi_{4}$ & 2.844 & 1.349 & 2.686 & 3.382 & 0.763 & $\pi / 2$ \\
\hline$\pi_{5}=\pi_{6}$ & 3.796 & $7.784^{* *}$ & 3.406 & 2.945 & 5.145 & $2 \pi / 3$ \\
\hline$\pi_{7}=\pi_{8}$ & $5.737^{* *}$ & $7.055^{* *}$ & 3.246 & 3.233 & 7.244 & $\pi / 3$ \\
\hline$\pi_{9}=\pi_{10}$ & 3.964 & $7.198^{* *}$ & 3.292 & $9.277^{* *}$ & $8.122^{* *}$ & $5 \pi / 6$ \\
\hline$\pi_{11}=\pi_{12}$ & 4.309 & 5.559 & 1.778 & 0.821 & 5.326 & $\pi / 6$ \\
\hline T(Lags) & $74(12)$ & $74(12)$ & $74(12)$ & $74(12)$ & $74(12)$ & \\
\hline \multicolumn{7}{|c|}{ Note: ${ }^{* *}$ indicates significance at 5 percent probability } \\
\hline
\end{tabular}

Table 2 presents further results of the evaluation of the univariate time series properties of price series of the markets under study.

Table 2: Results of Unit Root Test

\begin{tabular}{lcccc}
\hline Markets & ADF Level & Diff. & KPSS Level & Diff. \\
\hline Accra & -2.44 & $-9.11^{* * *}$ & 0.189 & $0.082^{* *}$ \\
Kumasi & -3.02 & $-9.54^{* * *}$ & 0.201 & $0.022^{* *}$ \\
Techiman & -2.72 & $-7.15^{* * * *}$ & 0.264 & $0.129^{* *}$ \\
Wa & -2.78 & $-6.48^{* * *}$ & 0.223 & $0.070^{* *}$ \\
Tamale & -3.27 & $-12.21^{* * *}$ & 0.178 & $0.027^{* *}$ \\
\hline
\end{tabular}

From table 2 the test results indicate that the null hypothesis of a unit root could not be rejected at levels for all the markets series. At difference however, the null hypothesis of unit root was rejected at $1 \%$ significance level for the ADF test. Similar results were produced by the KPSS test. It also rejected the null of stationarity at levels for all the markets and failed to reject the null hypothesis at first difference at 95\% confidence level. In summary, the ADF and KPSS tests provided evidence for unit root at the zero frequency, which implied that the yam price series in the various markets were integrated of order one I(1).

Cointegration: In this study, we focused on the possibilities of asymmetric adjustments (non-linearity) and threshold co-integration other than assuming symmetric and linear relationships as economic data are generally nonlinear in nature due to switching policy strategies, technical innovations, human behavior and dynamics of economic processes. Thus, Hansen and Seo's (2002) test was used to evaluate the linear cointegration model against the threshold cointegration model. The test results are shown in Table 3 below as Sup-LM statistics.

Table 3: Results of Hansen and Seo Test

\begin{tabular}{lllll}
\hline Markets & TA & TK & TT & TW \\
\hline Sup-LM statistics & 21.36 & 22.309 & 27.47 & 24.46 \\
P-Value & 0.05 & 0.017 & 0.00 & 0.04 \\
\hline
\end{tabular}


The results indicate that the other yam markets in relation to the reference market exhibit a threshold cointegration, suggestion the possibility of non-linear adjustments towards equilibrium. In this regard, the momentum threshold autoregressive model (M-TAR) was estimated to analyze threshold co-integration and asymmetric adjustment behaviors of the markets. The results of the threshold autoregressive models are presented in Table 4. The results indicate that all the markets pairs are cointegrated with a mixed adjustment (symmetric and asymmetric) processes towards equilibrium in the long-run and some response more swiftly to price shocks that stretch profit margin than price shocks that squeeze the margin. The Techiman-Kumasi (TA) and Techiman-Tamale (TT) relationships for instance respond rather more swiftly to deviations that squeeze profit margins. Many previous studies found similar asymmetric relationships in agricultural commodity markets (see Abdualai, 2000; Acquah, 2012; Amikuzuno et al., 2013; Blay et al., 2015; Cramon, 1998; Hahn, 2010; Peltzman 2000). The near symmetric adjustment towards equilibrium between Techiman and Kumasi can be explained by the closeness of the two markets, as traders in Kumasi obtain their supply from Techiman implying that price signals in one of the markets are easily transmitted to the other.

The point estimates for Techiman-Accra markets pair (TA) and Techiman-Wa (TW) are found to be ( $\rho_{2}=-$ 0.390 and -0.402$)$ and $\left(\rho_{2}=-0.211\right.$ and -0.268 ) respectively indicating at convergence of approximately $40 / 40$ percent of positive deviations and $21 / 27$ percents of negative deviations from the equilibrium will be corrected within a month. The markets exhibit relatively weak adjustments for negative deviations as compared to the positive deviations indicating a faster adjustment process toward equilibrium when the price difference (spread) deviates above the equilibrium. These markets are relatively efficient as the dynamics are consistent with market equilibrium theory (Abunyuwah, 2013; Barret and Li, 2002) compared to the others that exhibit the opposite adjustment dynamics. The asymmetric adjustments which imply market imperfections can be attributed to the fact that price determination is strongly influenced by the trader's associations rather than perfect competition (demand-supply) markets that are normally associated with barrier-free trading. Yam markets are controlled by market women, especially in the urban cities where majority of the consumption takes place with either little or no production. These market women under one association and queen, at specific periods collude to influence the price mechanism.

Table 4: Results from M-TAR Model

\begin{tabular}{|c|c|c|c|c|}
\hline Variable & TA & TK & TT & TW \\
\hline$\rho_{1}$ & $\begin{array}{l}-0.390^{* * *} \\
{[-8.412]}\end{array}$ & $\begin{array}{l}-0.204^{* * *} \\
{[-7.251]}\end{array}$ & $\begin{array}{l}-0.113^{* *} \\
{[-7.639]}\end{array}$ & $\begin{array}{l}-0.402 \text { ** } \\
(-3.247)\end{array}$ \\
\hline$\rho_{2}$ & $\begin{array}{l}-0.211^{* *} \\
{[-6.590]}\end{array}$ & $\begin{array}{l}-0.413^{* * *} \\
{[-5.530]}\end{array}$ & $\begin{array}{l}-0.370^{* * *} \\
{[-5.543]}\end{array}$ & $\begin{array}{l}-0.268^{* *} \\
(-4.183)\end{array}$ \\
\hline$\rho_{1}=\rho_{2}=0$ & $\begin{array}{l}7.983^{* * *} \\
(0.01)\end{array}$ & $\begin{array}{l}9.692^{* * *} \\
(0.000)\end{array}$ & $\begin{array}{l}6.502^{* *} \\
(0.002)\end{array}$ & $\begin{array}{l}13.473^{* * *} \\
(0.000)\end{array}$ \\
\hline$\rho_{1}=\rho_{2}$ & $\begin{array}{l}4.664^{* *} \\
(0.032)\end{array}$ & $\begin{array}{l}2.772^{*} \\
(0.098)\end{array}$ & $\begin{array}{l}4.553^{* *} \\
(0.035)\end{array}$ & $\begin{array}{l}0.958 \\
(0.329)\end{array}$ \\
\hline Lags & 2 & 3 & 5 & 3 \\
\hline $\operatorname{LB}(4)$ & 0.994 & 0.321 & 0.351 & 0.515 \\
\hline LB(8) & 0.966 & 0.578 & 0.297 & 0.164 \\
\hline
\end{tabular}

Price Transmission Dynamics: The price transmission dynamics of yam markets prices were studied by employing two regime TVEC model. The results of the TVECM are presented in Table 5 below. The results for Techiman-Accra markets combination from the TVECM through the search procedure yields a threshold parameter $(\Psi)$ of 24 which can be expressed as arbitrage cost. This implies that adjustment from disequilibrium towards the long-term equilibrium will occur when the arbitrage opportunities are above Gh\$24(US\$5.2) between both markets. For adjustments in response to positive shocks to occur, the absolute price change from the long-term equilibrium should be above Gh\$24 to cover average cost of transportation/transactions cost of the commodity between the two markets. The threshold vector error 
correction model revealed that for the Techiman-Accra markets equations, both markets had significant error correction terms for positive and negative deviations from disequilibrium towards equilibrium.

The point estimates for the adjustment parameters imply that Accra market adjusts to clear about $63.6 \%$ of the $39 \%$ positive shocks and 67.8 of $21.1 \%$ of negative shocks of price change from Techiman. The results also revealed that when an external shock is exerted in the Accra market, Techiman market will respond to eliminate approximately $51.2 \%$ of positive shocks and $44.7 \%$ of negative shocks within a month. Thus, at lower price spread where profit margins are squeezed, fast adjustment towards long-run equilibrium occurs in Techiman market. This implies the suppliers (farmers) will regulate the quantity of the commodity to be supplied to the market (speculation). In both markets, there was fairly symmetrical adjustments response to positive deviations from the equilibrium compared with negative deviations. Conversely, positive and negative deviation in the supplier market (Techiman) requires approximately 2 months (half-life $(\lambda)$ of 1.68 and 1.87 respectively) to be fully digested when there is a price shock in the consumer market (Accra). Similarly, the results revealed that Kumasi market responds significantly to positive and negative deviations from the long-term disequilibrium. Thus if deviations are above the arbitrage cost, an error correction terms $\left(\phi^{\text {tec ஐiman }}=0.669\right)$ for Techiman market implying that markets agents in the market respond rapidly to positive price shocks than negative shocks $\left(\phi^{\text {tec®iman }}=0.501\right)$.

Kumasi market responds moderately to both positive deviation $\left(\phi^{\text {kumasi }}=-0.473\right.$ ) and negative deviation $\left(\phi^{\text {Kumasi }}=0.447\right)$ towards long-term equilibrium. The result is expected because the market agents in the Techiman (supplier market) will respond faster to any shock that stretches their profit margins than shock that squeezes profit. The half-time ${ }^{1}$ necessary to correct the disequilibrium in Kumasi is around 2 months $(\lambda=1.79)$ when there is a positive price shock from Techiman while Techiman responds swiftly to adjust within 1 month 10 days $(\lambda=1.36)$ when there is a positive shock from Kumasi market. The long term coefficients of elasticity $(\beta)$ are $0.321,0.172,0.115,0.03$ for the markets in relation to the reference (Techiman) which may be thought of as price transmission elasticity estimate. This implies that a unit percentage increase in the prices of yam in Techiman market will bring about 32, 17, 11.5 and 3 percentages increases in the prices of yam in Accra, Kumasi, Tamale and Wa markets respectively. Furthermore, Tamale and Wa respond to positive and negative shock respectively as a result of external price shocks created by price changes in Techiman market. In Tamale markets, there was faster adjustments to positive deviations from the disequilibrium than negative ones; implying positive asymmetry while Wa market exhibited faster adjustment to negative perturbation to negative shocks as created by price changes in Techiman.

Table 5: Results of Threshold Vector Error Correction Model

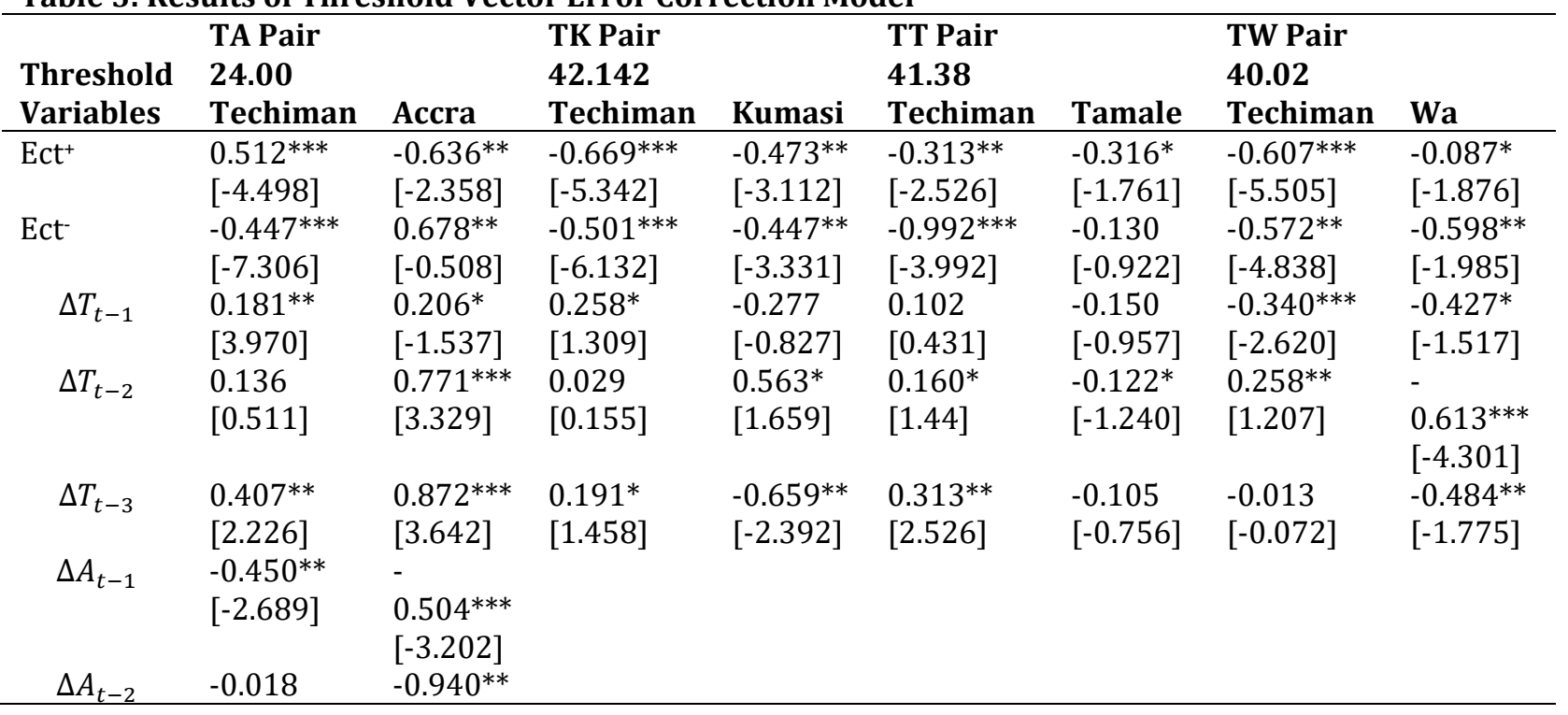

${ }^{1}$ Half Time was computed as: $\mathrm{HT}=\frac{\operatorname{In} 0.5}{\operatorname{In}(\alpha+1)}$ 


\begin{tabular}{|c|c|c|c|c|c|c|c|c|}
\hline \multicolumn{9}{|c|}{$\begin{array}{l}\text { Journal of Economics and Behavioral Studies (ISSN: 2220-6140) } \\
\text { Vol. 12, No. 3, pp. 23-31, June 2020 } \\
\end{array}$} \\
\hline & {$[-0.098]$} & {$[-5.204]$} & & & & & & \\
\hline$\Delta A_{t-3}$ & $\begin{array}{l}-0.342 \\
{[-1.797]}\end{array}$ & $\begin{array}{l}-0.274^{*} \\
{[-1.987]}\end{array}$ & & & & & & \\
\hline$\Delta K_{t-1}$ & & & $\begin{array}{l}0.154^{*} \\
{[1.952]}\end{array}$ & $\begin{array}{l}-0.294^{* *} \\
{[-2.190]}\end{array}$ & & & & \\
\hline$\Delta K_{t-2}$ & & & $\begin{array}{l}0.475^{* * *} \\
{[5.592]}\end{array}$ & $\begin{array}{l}- \\
0.674^{* * *} \\
{[-4.673]}\end{array}$ & & & & \\
\hline$\Delta K_{t-3}$ & & & $\begin{array}{l}0.258^{* *} \\
{[2.561]}\end{array}$ & $\begin{array}{l}-745^{* * *} \\
{[-4.344]}\end{array}$ & & & & \\
\hline$\Delta T A_{t-1}$ & & & & & $\begin{array}{l}-0.270^{*} \\
{[-1.163]}\end{array}$ & $\begin{array}{l}- \\
0.841^{* * *} \\
{[-5.454]}\end{array}$ & & \\
\hline$\Delta T A_{t-2}$ & & & & & $\begin{array}{l}-0.220 \\
{[-0.959]}\end{array}$ & $\begin{array}{l}-0.550^{* *} \\
{[-3.521]}\end{array}$ & & \\
\hline$\Delta T A_{t-3}$ & & & & & $\begin{array}{l}-0.219^{*} \\
{[-1.407]}\end{array}$ & $\begin{array}{l}-0.098 \\
{[-0.770]}\end{array}$ & & \\
\hline$\Delta W_{t-1}$ & & & & & & & $\begin{array}{l}-0.018 \\
{[-0.167]}\end{array}$ & $\begin{array}{l}- \\
0.881 * * * \\
{[-6.384]}\end{array}$ \\
\hline$\Delta W_{t-2}$ & & & & & & & $\begin{array}{l}-0.018 \\
{[-0.784]}\end{array}$ & $\begin{array}{l}-0.736^{* *} \\
{[-4.685]}\end{array}$ \\
\hline$\Delta W_{t-3}$ & & & & & & & $\begin{array}{l}-0.148^{*} \\
{[-1.325]}\end{array}$ & $\begin{array}{l}-0.139 \\
{[0.921]}\end{array}$ \\
\hline$\phi^{+}=\phi^{-}$ & $\begin{array}{l}6.252^{* *} \\
(0.012)\end{array}$ & $\begin{array}{l}0.887 \\
(0.20)\end{array}$ & $\begin{array}{l}0.206 \\
(0.651)\end{array}$ & $\begin{array}{l}3.685^{* *} \\
(0.05)\end{array}$ & $\begin{array}{l}0.836 \\
(0.362)\end{array}$ & $\begin{array}{l}5.041^{*} \\
(0.026)\end{array}$ & $\begin{array}{l}0.790 \\
(0.41)\end{array}$ & $\begin{array}{l}2.272^{*} \\
(0.09)\end{array}$ \\
\hline$\beta^{2}$ & $0.321^{* *}$ & & $0.172^{* *}$ & & $0.115^{* * *}$ & 39] & $0.03^{* *}[4$ & \\
\hline
\end{tabular}

Further analysis was conducted to examine the short and long-run price dynamics. The results revealed that the price changes in Accra market was influenced by its internal short-run forces and were as the short-run prices changes in Techiman. Conversely, Kumasi market had asymmetric short-run effect on Techiman prices. Similarly, distributed short-run asymmetric effect was found for Techiman for its own price with symmetric effect on Tamale and Wa market. However, there was asymmetric path of adjustment towards long-run equilibrium in Accra, Tamale and Wa markets due to price dynamics created by Techiman market. Kumasi exhibited symmetric path of adjustment implying that market player's response quickly with equal momentum to positive and negative shocks from price changes in Techiman market.

This result supports Abdulai (2000) and Blay et al. (2015) who reported asymmetric adjustment in Ghanaian maize and sorghum and millet market respectively. Finally, the results of the granger causality model reveal that in Accra and Kumasi, there is evidence of bi-directional causality effects from the supplier market to the consumer market and vice versa. Tamale and Wa exhibit a unidirectional causality running from Tamale and Wa to Techiman. This may be explained by the fact that the markets players (farmers, middlemen) use information from each other when speculating their price with primary focus on the price level in the supplier or consumer markets. Notwithstanding the flow of information, the price adjustment responses are asymmetrically transmitted through the markets especially to the supplier markets where adjustments tend to squeeze the profit margin of the middlemen.

${ }^{2} \phi^{+}=\phi^{-}$test the equilibrium adjustment path of asymmetric effect. $*, * *, * * *$ denotes significance at the $10 \%, 5 \%$ and $1 \%$ level respectively. The estimates in the carry bracket are the T statistics values of their corresponding estimated coefficient and $\beta$ is long-run estimate of transmission. 


\section{Conclusion}

The study focused on the analysis of market integration and price transmission dynamics to infer market efficiency and functionality of the Ghanaian yam markets. The M-TAR model was employed to examine the degree of spatial market integration among yam markets in Ghana. The price transmission adjustment processes were analyzed through nonlinear error correction model with threshold cointegration incorporated (TVECM). The markets for the commodity considered for the study were found to be highly integrated. The coefficients from the MTAR models revealed an asymmetric adjustment processes with mixed pattern of outcomes with respect to speed and degree of adjustments. Some of the markets exhibited faster adjustment for positive deviation than negative deviations and vice versa. We recommend that policy strategies be directed to improving market communication and infrastructure accessibility and regulating activities of middlemen since the nature of asymmetric price adjustments found in this study is associated with market power and inefficiency. These are to improve agricultural food market structure, conduct and performance which, in effect, will provide fair producer prices and value for money for producers and consumers respectively.

\section{References}

Abdulai, A. (2000). Spatial Price Transmission and asymmetry in the Ghanaian Maize Market. Journal of Development Economics, 63, 327-349.

Abdulai, A. (2002). Using Threshold Cointegration to estimate asymmetric Price Transmission in the Swiss Pork Market. Journal of Applied Economics, 34, 679-687.

Abunyuwah, I. (2008). Market Integration Analysis and Time Series Econometrics-Conceptual Insights from Markov-Switching Models. Doctoral Dissertation: Faculty of Agricultural Sciences Georg-AugustUniversity of Göttingen, Germany.

Abunyuwah, I. (2013). Implications of Conceptual and Data Complexities on Time-Series Econometric Applications in Market Integration Analysis. Studies in Agric Economics, 115(1) 33-38.

Acquah, De G. H. (2012). A Threshold Cointegration Analysis of Asymmetric in the Ghanaian Maize Markets. Russian Journal of Agricultural and Socio-Economic Sciences, 8(8).

Alderman, H. (1993). Intercommodity price transmittal: Analysis of markets in Ghana. Oxford Bulletin of Economics and Statistics, 55(1), 43-64.

Amikuzuno, J. (2009). Spatial Price Transmission and Market Integration between Fresh Tomato Markets in Ghana: Any Benefits from Trade Liberalization? Tropentag, 6-8.

Amikuzuno, J., Gazali, I. \& Edward, B. D. (2013). Price Trans-mission between Imported and Local Rice Markets in a Liberalized Economy: Are Ghana's Rice Wars Just Much I Do about Nothing? J. Econ. Sust. Dev, 4(20), 1-15.

Badiane, O. \& Shively, G. (1998). Spatial integration, transport costs, and the response of local prices to policy changes in Ghana. Journal of Development Economics, 56(2), 411-431.

Balke, N. S. \& Fomby, T. B. (1997). Threshold Cointegration. International Economic Review, 38, 627-645.

Barrett, C. B. \& Li, J. R. (2002). Distinguishing between equilibrium and integration in spatial price analysis. American Journal of Agricultural Economics, 84, 292-307.

Baulch, B. (1997). Transfer costs, spatial arbitrage, and testing for food market integration. American Journal of Agricultural Economics, 79(2), 477-487.

Blay, J. K., Subba Rao, D. V. \& Kumari, R. V. (2015). Price Dynamics and Market integration of Sorghum and Millet Markets in Ghana. Research Journal of Agriculture and Forestry Sciences, 3(9), 11-21.

Chan, K. S. (1993). Consistency and Limiting Distribution of the Least Squares Estimator of a Threshold Autoregressive Model. The Journals of Statistics, 21, 520-533.

Enders, W. \& Siklos, P. L. (2001). Cointegration and threshold adjustment, Journal of Business \& Economic Statistics, 19, 166-167.

FAOSTAT. (2014). Global yam production. Rome, Food and Agriculture Organization [FAO].

Hahn, W. F. (2010). Dynamic and Asymmetric Adjustment in Beef and Pork Prices in USA market. Selected Paper prepared for presentation at the Agricultural \& Applied Economics Association's 2010 AAEA, CAES \& WAEA Joint Annual Meeting, Denver, Colorado.

Hansen, B. E. \& Seo, B. (2002). Testing for Two-Regime Threshold Cointegration in Vector Error Correction Models, Journal of Econometrics, 110, 293-318. 


\section{Journal of Economics and Behavioral Studies (ISSN: 2220-6140)}

Vol. 12, No. 3, pp. 23-31, June 2020

Hylleberg, S., Engle, R. F., Granger, C. W. J. \& Yoo, B. S. (1990). Seasonal Integration and Cointegration. Journal of Econometrics, 44, 215-238.

Jawadi, F., Million, N. \& El Hédi Arouri, M. (2009). Stock market integration in the Latin American markets: further evidence from nonlinear modeling, Economics Bulletin, 129(1), 162-168.

Kwiatkowski, D., Phillips, P. C. B., Schmidt, P. \& Shin, Y. (1992). Testing the null hypothesis of stationarity against the alternative of a unit root: How sure are we that economic time series have a unit root? Journal of Econometrics, 54, 159-178.

Lemma, H. R. \& Singh, R. (2015). Testing for Price Co-Integration between Producers and Retailers: Evidence from Ethiopian Milk Market. Scientific Research Publishing, 7, 1-9.

Mensah-Bonsu, K., Agyeiwaa-Afrane, A. \& Kuwornu, J. K. M. (2011). Efficiency of the plantain marketing system in Ghana: A co-integration analysis. Journal of Development and Agricultural Economics, 3(12), 593-601.

Peltzman, S. (2000). Prices Rise Faster than they fall, Journal of Political Economy, 108(3), 466-502.

Von Cramon-Taubadel, S. (1998). Estimating asymmetric price transmission with the error correction representation: an application to the German pork market. Eur. Rev. Agric. Econ, 25, 1-18.

Zapata, H. O. \& Gauthier, W. M. (2003). Threshold Models in Theory and Practice. Selected Paper prepared for presentation at the Southern Agricultural Economics Association Annual Meeting, 1-5. 